\title{
An Approach for Future-Oriented Framework Design: A Tool for Design Research
}

\author{
Akhilesh Kumar Singh ${ }^{1, *}$, Giri Vijay Temmanaboina ${ }^{2}$, Prasanth Gummalla ${ }^{3}$, and Pramod Kumar $^{4}$ \\ 1,2,3,4Mechanical Engineering Department, Aditya College of Engineering \& Technology, Surampalem, Andhra Pradesh, India
}

\begin{abstract}
Metals and Metals-alloys play a significant role in the everyday life of researchers and also in industrial applications to develop a new framework product. New development of tool and techniques help researchers to do their work smoothly. Multi-purpose machines mainly help researchers to do framework design and research as per need and it will save both cost and time. In this paper, the main aim is to develop a machine-stand that performs machine operations in a single column (either side of the column). The operations are cutting, grinding, and drilling. The purpose of the machine is to support researchers in their research work, with high precision to drill without any (human error) vibrations and to cut the work-samples without edges loses. The machine is designed for portable purposes, that can be used in laboratory, field, workshop, and workplace, etc. to do operations of cutting and drilling in various places. The same machine is used for multi-operation, instead of using separate fixed flame machines such as cutting, grinding, and drilling machines. The machine operates through power sources with liquid coolant lubricant and the operations performed simultaneously or individually
\end{abstract}

\section{INTRODUCTION}

Today in this world, as per the demand for new products and materials in the market is more. To manufacture new products and materials various new methods were developed for new product forecasting. To develop the new product as per the requirement of costumers [1]. The tool and techniques demand is also increased to manufacture a new product as per demand with their accuracy [2]. Similarly, in industries, small-workshops workplaces, engineering institutions, using different types of new machines for their research and product development, done by different operations (such as drilling, cutting, grinding, etc.) depending upon the type of work of services [3].

Fabrication and manufacturing of new products that directly depend on the types and features of machines used for work and cost. Generally, the work is done using 5M (i.e. Manpower, Machine, Method, Money, and Measurement) [4]. The outputs of any machines should be fulfilling desired the need for work such as surface finish, accurate size produce without any mismatch, etc. While doing any operations, the workpiece should be clamped properly on the table bed of the one machine to other machines tills completion of the works which consume time to place at the accurate place, regarding seeing such problems many researchers work and still working on, to improve the mechanisms of the machine and work [5]. In engineering institutions, various materials being used for research work purpose to help industries improve friendly relationships between institutions and industries which directly improve the productivity of industries and indirectly the economics of any country also by doing good research. The safety rules used for handling machines and precautions should be maintained to prevent any accident in their manufacturing different products and also without any direct or indirect failure and defects [6].

In the present research framework, it is designed for a future-oriented framework for the scientific and engineering domain. The machine-stand is designed with a 360-degree rotating table, coolants to cool the tool and workpiece, and also two clamp-vices have placed both sides of the machine holders for machining operations. This machine applicable to metallic materials to the removal of unwanted material in research-oriented work purposes such as drilling, grinding, and cuttings.

\subsection{Classification of drilling machines}

Many types of drilling machines are available in the market as per the need of work to produce holes in the workpieces [4-6] and drill machines are classified as:

- Portable drill machine

- Sensitive drill machine

- Deep hole drill machine

- Upright drill machine

- Radial drill machine

- Multiple spindle drill machine

- Hand drill machine

- Gang drill machine

- Bench type of drill machine

- Automatic/Numerically controlled drill machine, etc.

\footnotetext{
* Corresponding author: akhileshkr.singh@,hotmail.com
} 


\subsection{Classification of Cutting and grinding machines}

According to the need and purpose of work, the cutting and grinding machines are used to do the work on the specimens. Cutting Tools are classified as two types i.e. single-and multiple-point tools. As per operation, it can be classified into three categories [7] such as:

- Manually operated machine

- Semi-Automatic operated machine

- Fully-Automatic or Computer control operated machine

\subsection{Motivation toward work}

The aim of work to design and fabricate such type of multipurpose machines in one stand structure column, that is used for performing operations are:

- Drill produced accurately without (human errors) vibration

- Cutting and Grinding purpose

\subsection{Problem Statement}

- For welding temperature, numerical analysis purpose thermocouple is used, for that need to produce at least $1 \mathrm{~mm}$ holes at accurate size without mismatching.

- Portable machine with less space.

- Traditional machines are very costly and require more space.

- The machine can be used any every as per needs in which traditional machines are fixed in one place and their power consumption is more.

\section{Design Methodology}

The software CATIA V5 is used to design for desired equipment for multipurpose machines. CATIA V5 is a more popular CAD (computer-aided design) engineering software that used to solve engineering design problems and analyses. With the help of this software, a machine framework designed for the individual components and assembled parts as shown in Fig. 1. With the help of different workbenches in this software (i.e., like part designing, assembly, drafting, sketcher, etc) desired design output accurately generated easily. With the help of sketcher \& part design workbenches layout diagram designed for machine stand. Drafting workbench is used to provide dimensions for the frame by producing different views of it.

The objective of this future-oriented framework designs a machine-stand that can-do different applications of operations in one machine frame-column stand are successfully designed after considering all the necessary safety factors. The machine can be used as per need of work in laboratory, workplace, and in-service fields.

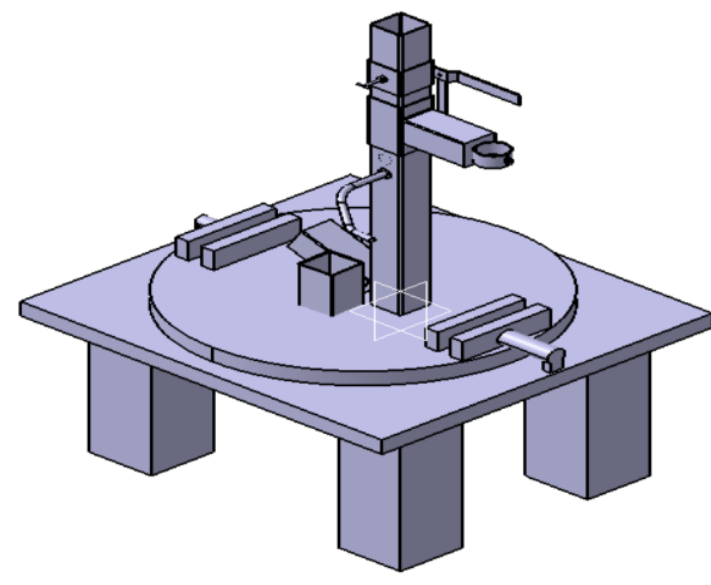

Fig. 1. Machine-stand Isometric view design

\section{Experiment Procedure}

In traditional drilling machines, when working with a small workpiece, clamping problems arise during drilling operations and few specimen parts cannot drill properly. So, the alternate source was the hand drills machine. In hand drill machines while operating human errors were observed i.e. accurate diameter hole size alignment problem arises. After observing such a problem, a new machine flame-stand is designed and fabricated for research-oriented work purposes, and laboratory uses. Design of a single stand for different operations such as cutting, grinding, and drill operations. In a drilling operation, it used to bring the arm down and perform an operation at any desired place. Either side of the rod it will perform two different operations at one place with the help of two mechanisms that will be done at a time.

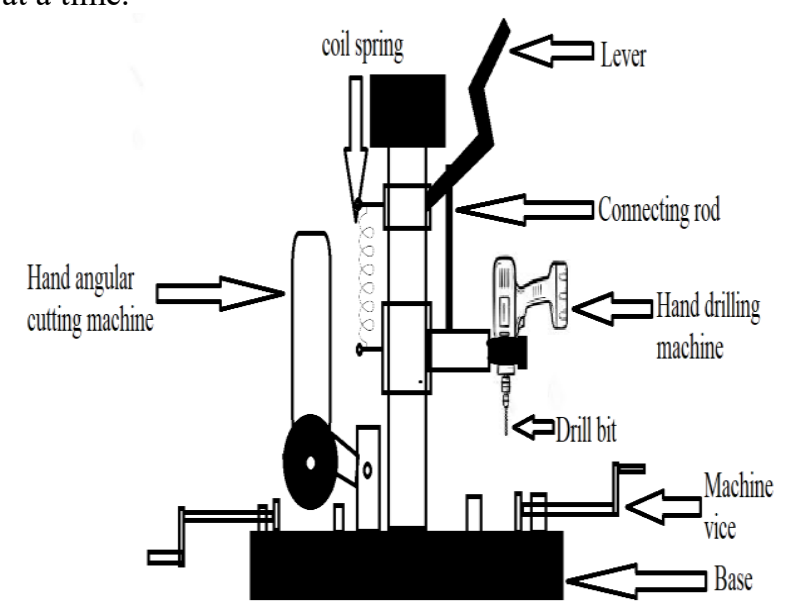

Fig. 2. Schematic view of Machine-stand design

In this research work, one operation hand drill machine is used, as per research-oriented work purposes to produce geometry holes in the object without human error, as shown in Fig. 2. As per the design of the portable drill machine-stand, the linear motion is provided to the drill machine to feed towards the workpiece. To remove unwanted material from a 
workpiece in the form of chips from the hole, coolant pipes were placed. Cutting fluid will flash the chips and also remove heat to cool/improve the working machining operation. It also reduces the friction at the tool-chip interface and the work-frank regions. The coolant tank is placed at the bottom of the table. Cutting fluids will be circulated with the help of motor and pipe-lines and also in some cases of hard material operations. The common operation can be performed by this drill machines are drilling, boring, reaming, tapping, counterboring, spot facing, and countersinking.

The second operation of machine-stand is used for cutting and grinding purposes and also it mechanizes, as per research-oriented work purposes to produce grove, cutting, edge geometry finish, etc. on the object without human error, as shown in figure 2. As per the design of the portable hand cutter machine is used. In this part, linear and to-and-fro motion is provided to cut the workpiece and remove unwanted material from a workpiece in the form of chips, and coolant pipes were placed to cool abrasive cutter blade and grinder wheels. The fluid will flash/remove the unwanted material such as chips and dust and also save from wear and tear.

Drilling (Cutting) speed and feed to the relative work can be measured [7] by

Cutting Speed $=\Omega$ D.N. $/ 1000 \mathrm{~m} / \mathrm{min}$.

Where,

$$
\begin{aligned}
& \mathrm{D}=\text { Dia. Of drill in } \mathrm{mm} \\
& \mathrm{N}=\text { Work speed in r.p.m. }
\end{aligned}
$$

Tool life can be analysised with the F.W. Taylor's Tool Life equation:

$$
V x \operatorname{Tn}=C
$$

Where,

$$
\begin{aligned}
\mathrm{V}= & \text { Cutting speed in } \mathrm{m} / \mathrm{min} . \\
\mathrm{T}= & \text { Tool life in min. } \\
\mathrm{n}= & \text { Tool life index, (whose value depends on the } \\
& \text { material of the cutting tool } \\
= & 0.1-0.15, \text { high speed steel tools } \\
= & 0.2-0.5, \text { Tungsten/cemented carbide tools } \\
= & 0.6-1.0 \text {, ceramic tools } \\
\mathrm{C}= & \text { Constant (A machining constant, which is } \\
& \text { numerically equal to the cutting speed in } \mathrm{m} / \mathrm{min} . \\
& \text { that would give a tool life of one minute). }
\end{aligned}
$$

\section{RESULTS AND DISCUSSIONS}

Directly and indirectly, if Engineering Institutions collaborate with industries, it may be useful for both sides to improve product quality with new tools and technologies. Engineering institutions and industrial relationships always developed new inventions. In Engineering Institutions, throughout the world, engineering (B.E./B.Tech./M.Tech.) students generate ideas, methodology, new formulas-concepts, etc. in their project works and they design and fabricates various innovative experimental works. According to their ideas, they develop new tools and techniques to support college laboratories as well as other students to do their experimental work and one example is shown in Fig. 3. Ph.D. researchers get more benefits after utilizing the fabricated machine in their research-oriented works. Machine-stand is utilized to cut samples and achieved good surface finish has been observed shown in Fig. $4 \mathrm{a}-$ $4 d$.

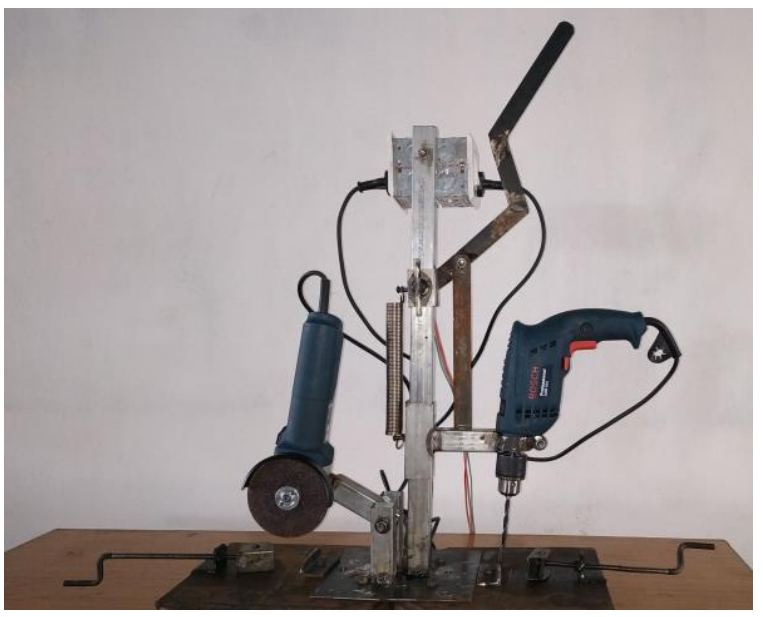

Fig. 3. Fabricated machine-stand along cutting, grinding and drill machines assembled.

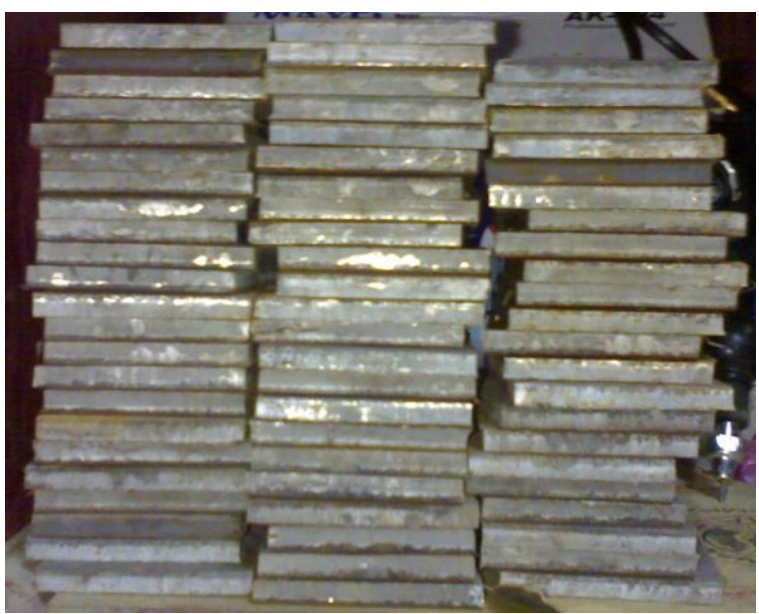

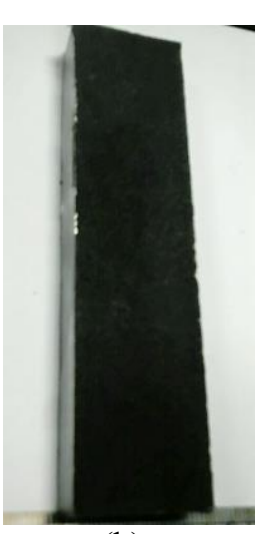

(b) (a)

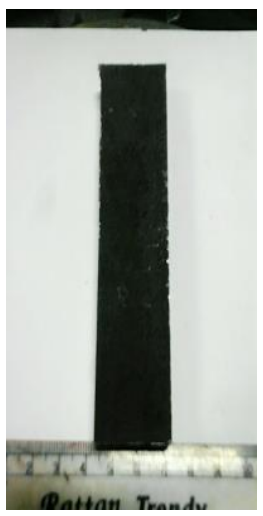

(c)
Fig. 4. (a) Number of samples were cut and prepaid as per need for research works, (b) and (c) Sample cut side \& top view good surface finished achieved without human error. 


\subsection{Sample Preparation}

To carry out the research work on steel plates material was cut into different shapes and sizes of the weld bead as per need by an abrasive cutter with a blade. These samples-specimens was used in various TIG welding was carried out (such as TIG, ATIG, FBTIG and HTRCFB-TIG) research experiments conducted and papers were published in high impacts journals [8-13], as shown in Fig. 5 (a) to (d) and Fig. 6. Show the thermocouple setup is used after drilling in weld specimens without human error. After TIG weld, welded samples-specimens were cut into different sized as per need to analysis effect on Microstructure and Grain Size, Hardness, grain size, etc. as shown in Fig. 7.
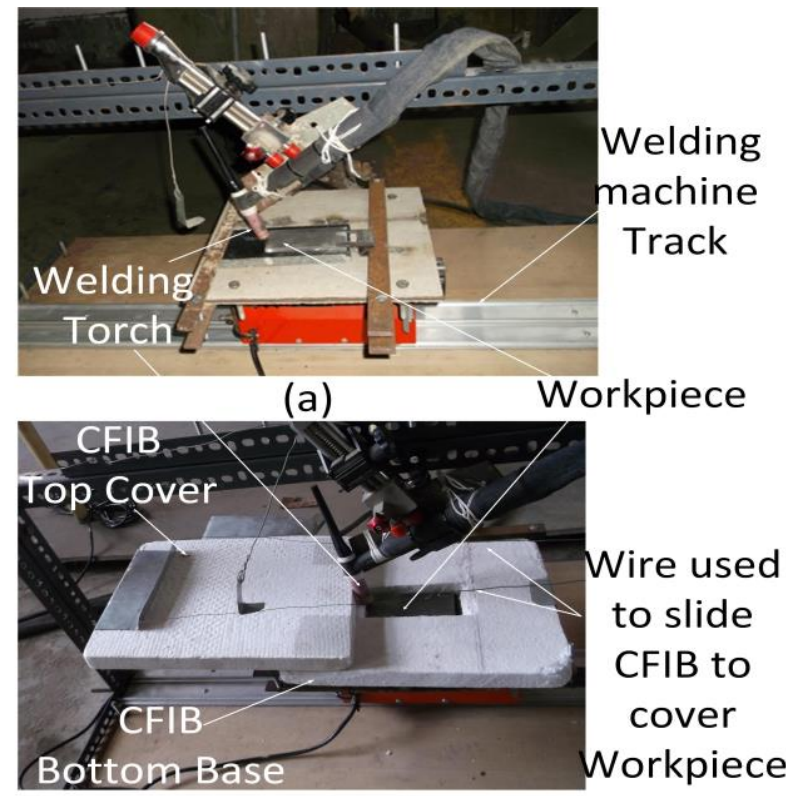

(b)

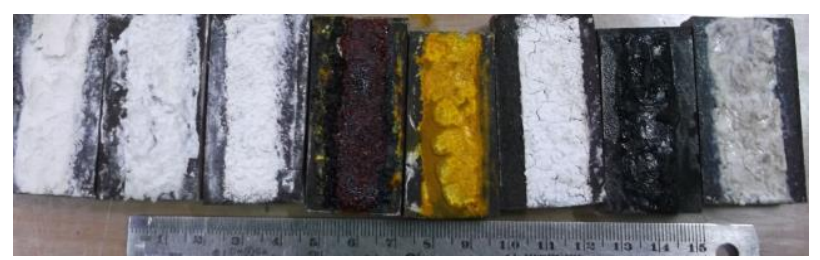

(c)

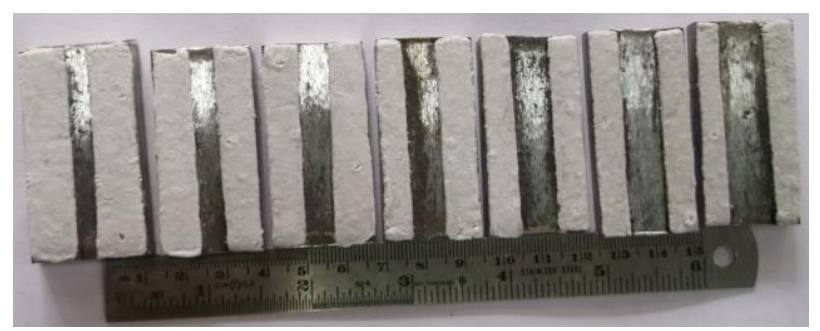

(d)

Fig. 5. Machine setup and Number of abrasive cutter cut specimens - good surface finished achieved without human error were used in ( $a \& b)$ TIG and HTRCFB-TIG (c \& d) ATIG and FBTIG samples

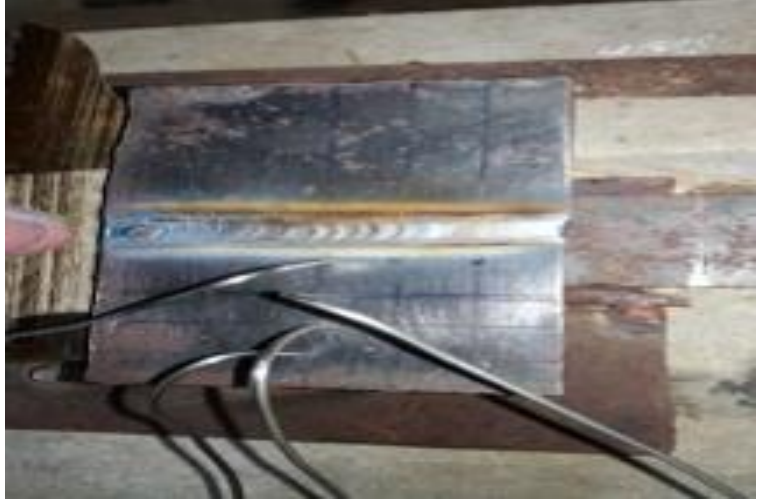

Fig. 6. Thermocouple setup is used after drill in weld specimens without human error.

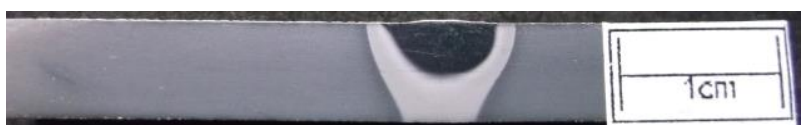

Fig. 7. Abrasive cutter cut specimens used after weld to analysis effect on Microstructure and Grain Size, Hardness, grain size.

\section{Conclusion}

The objective of this future-oriented framework designs a machine-stand that can-do different applications of operations in one machine frame-column stand is successfully fabricated after considering all the necessary safety factors and trails also have done on cutting, drilling and grinding operations as per need of works.

Generally, we have seen that in traditional machines do mostly do heavily work according to the capacity of the machine and due to continuous in service they need maintenance, repair, and replacing parts yearly which increases the cost. If a machine in under maintenance, students, engineers, and researchers research-works stopped. While observing such a problem this machinestand is developed to work with thin or thick specimens without dimensional loss and to achieve high accuracy which was successfully fabricated at low making costs, a type of machinery equipment purchased cost and low inventory costs for the research-oriented works (i.e. drilling, cutting, and grinding) purposes has successfully have been achieved.

\section{References}

1. Zhang, Haoqiang, Xibin Wang, and Siqin Pang. "A mathematical modeling to predict the cutting forces in microdrilling." Mathematical Problems in Engineering 2014 (2014).

2. Singh, Akhilesh Kumar, Vidyut Dey, and Ram Naresh Rai. "Mechanised TIG Welding Gives Consistent Bead Geometry, A Case Study." International Journal on Recent Technologies in Mechanical and Electrical Engineering 2, no. 8 (2015): 31-35. 
3. Chandrasekharan, V., S. G. Kapoor, and R. E. DeVor. "A mechanistic approach to predicting the cutting forces in drilling: with application to fiberreinforced composite materials." (1995): 559-570.

4. Kim, D.W., Cho, M.W., Seo, T.I. and Lee, E.S., 2008. Application of design of experiment method for thrust force minimization in step-feed micro drilling. Sensors, 8(1), pp.211-221.

5. Hasan, Mahadi, Jingwei Zhao, and Zhengyi Jiang. "A review of modern advancements in micro drilling techniques." Journal of Manufacturing Processes 29 (2017): 343-375.

6. Sengar, Shailesh S., Vaibhav Raghav, and Chadaram Srinivasu. "Design \& Fabrication of a Special Tool to Produce Square Hole." Procedia materials science 6 (2014): 1823-1836.

7. Srinivasa Rao D, Sandhya Rani MN, Sarfaraz Nawa z Syed and Suresh Kumar Tummala, E3S Web of Conferences 8701003 (2019)

8. Singh, Akhilesh Kumar, Vidyut Dey, and Ram Naresh Rai., Techniques to improveweld penetration in TIG welding (A review), Materials Today: Proceedings. 4.2 (2017) 1252-1259, https://doi.org/10.1016/j.matpr.2017.01.145

9. Akhilesh Kumar Singh, Tapas Debnath, Vidyut Dey \& Ram Naresh Rai, An Approach to Maximize Weld Penetration During TIG Welding of P91 Steel Plates by Utilizing Image Processing and Taguchi Orthogonal Array. J. Inst. Eng. India Ser. C. 98 (2017) 541-551, https://doi.org/10.1007/s40032016-0268-3

10. Akhilesh Kumar Singh, Vidyut Dey, Ram Naresh Rai \& Tapas Debnath, Weld Bead Geometry Dimensions Measurement based on Pixel Intensity by Image Analysis Techniques. J. Inst. Eng. India $\begin{array}{llll}\text { Ser. } & \text { C. } & 100 & \text { (2019) 379-384, }\end{array}$ https://doi.org/10.1007/s40032-017-0392-8

11. Singh, Akhilesh Kumar, Vidyut Dey, and Ram Naresh Rai, Study on the effect of high-temperature ceramic fiber insulating board to weld grade P-91 steel, Journal of Manufacturing Processes. 25 (2017) 1-7, https://doi.org/10.1016/j.jmapro.2016.09.006

12. Singh, A.K., Dey, V. \& Rai, R.N., A Study to Enhance the Depth of Penetration in Grade P91 Steel Plate Using Alumina as Flux in FBTIG Welding. Arab J Sci Eng. 42 (2017) 4959-4970, https://doi.org/10.1007/s13369-017-2605-0

13. Singh, Akhilesh Kumar, Mayank Kumar, Vidyut Dey, and Ram Naresh Rai, A Study to Increase Weld Penetration in P91 Steel During TIG Welding by using Activating Fluxes, In IOP Conference Series: Materials Science and Engineering. 225 (2017) 012099, https://doi.org/10.1088/1757$899 X / 225 / 1 / 012099$ 